\title{
UMA PESQUISA DE CAMPO SOBRE A INCIDÊNCIA DE ILUSTRAÇÕES NOS LIVROS DIRIGIDOS AO PÚBLICO ADULTO
}

\author{
Bruna Saddy \\ PUC-Rio \\ Jackeline Lima Farbiarz \\ PUC-Rio \\ jackeline@puc-rio.br
}

\begin{abstract}
Resumo: $\mathrm{O}$ artigo apresenta o resultado de uma pesquisa exploratória sistemática na qual se investigou a ocorrência de ilustrações nos livros dirigidos ao público adulto. O foco da pesquisa foi, através de amostragem, procurar traçar um pequeno panorama da atual situação do mercado editorial no âmbito da ilustração e traçar uma possível tendência. Foi constatada a baixa oferta de títulos de ficção ilustrados dirigidos para o público adulto, a diferenciação quanto à quantidade de ocorrências de ilustração nos livros de ficção e não-ficção, que existe uma maior porcentagem de títulos ilustrados na seção de mais vendidos do que na seção de lançamentos, e que não há concordância entre a academia, editoras e livrarias quanto às definições de gêneros literários.
\end{abstract}

Palavras-chave: livro ilustrado, leitura, ilustração, adulto.

\begin{abstract}
This article presents the result of a systematic exploratory research that investigated the occurrence of illustrations in books for adults. The goal was to elaborate, through sampling, a small overview, and to delineate a possible tendency in the field of editorial illustration. It was found that there is a very small supply of illustrated fiction oriented to mature audiences, that there are differing quantities of illustrated fiction and non-fiction titles, that there is a greater percentage of illustrated titles in the the best sellers section than in new releases section, and that there is no agreement among the academia, the editors and the bookstores about the definition of literary genres.
\end{abstract}

Key words: illustrated book, reading, illustration, adult. 


\section{INTRODUÇÃO}

Nesse artigo, apresenta-se o resultado de uma pesquisa exploratória sistemática na qual se investigou a ocorrência de ilustrações nos livros dirigidos ao público adulto. O foco da pesquisa foi procurar fazer um pequeno panorama por amostragem e traçar uma possível tendência no âmbito da ilustração editorial.

O livro ilustrado é, atualmente, um objeto comumente associado ao universo infantil, no entanto a sua existência é anterior a da criação do conceito de infância. Enquanto esta noção começa a surgir no século XVII com Descartes, que propõe uma separação da vida adulta e da infância por questões biológicas e de "paixões da alma", o livro ilustrado, nas formas de códex, rolo de papiro ou até tábuas de cera, pedra e madeira, pode ser encontrado desde a Antiguidade. Embora existam títulos de literatura ilustrados dirigidos ao público adulto atualmente, como O Orfanato da Srta. Peregrine para Crianças Peculiares e Laranja Mecânica, na elaboração desta pesquisa toma-se como hipótese que o grande público não tenha conhecimento de sua oferta e que esta é reduzida.

Afim de verificar a incidência atual de ilustração nos livros oferecidos ao público leitor adulto, nos dias 8 e 9 de abril de 2014 foi realizada uma pesquisa de campo exploratória inicial na Livraria Cultura do Centro da cidade do Rio de Janeiro. Este local foi escolhido por ser uma loja de uma grande e famosa cadeia de livrarias, localizada em um dos pontos mais democráticos da cidade, tanto em acesso quanto em diversidade de pessoas.

No primeiro dia, a pesquisa deu-se no estande mais próximo da entrada da loja e que faz às vezes de vitrine, a mesa dos lançamentos e dos livros de ocasião (vinculados a datas comemorativas) ${ }^{1}$. Esse é um lugar estratégico no qual os livreiros tentam posicionar os produtos que eles consideram que mais tenham chances de chamar atenção dos consumidores e passantes e, ao mesmo tempo, apresentar a eles os novos produtos. Esta amostra deu à pesquisa a oportunidade de analisar livros de diversos gêneros e editoras, sem o risco de ser parcial na seleção.

No segundo dia, a atenção foi focada no estande de mais vendidos. Enquanto o estande dos lançamentos se concentra especialmente em literatura, o de mais vendidos apresenta os livros mais comprados de diversas seções daquela unidade específica. Embora este estande tenha menos visibilidade por seu posicionamento menos próximo à entrada da loja, ele se encontra na passagem para os demais ambientes então ainda há muita circulação de pessoas.

Levando em consideração que o universo dessa pesquisa engloba somente os consumidores e livreiros da Livraria Cultura, unidade Centro do Rio de Janeiro, em um período específico de tempo, é possível afirmar, com as devidas proporções e restrições, que os livros do primeiro estande, o de lançamentos, representam a expectativa e as apostas dos livreiros e editores sobre o que vai atrair os consumidores, enquanto que o segundo estande, o de mais vendidos, forneceu uma visão sobre o desejo e as efetivas aquisições dos próprios leitores. ${ }^{2}$

\footnotetext{
${ }^{1}$ O período no qual a pesquisa foi realizada, início de abril de 2014, marcou a data história dos 50 anos do golpe militar e é um fator que possivelmente influencia a grande oferta observada de livros sobre a ditadura militar brasileira.

${ }^{2}$ Alguns possíveis tópicos de questionamento seriam que, mesmo que a expectativa dos livreiros e editores fosse exatamente coincidente com o desejo dos leitores, a loja não colocaria exemplares "repetidos" em espaços tão próximos e também o fato conhecido de que as editoras "pagam" pelo espaço de exibição em algumas livrarias, assim como se dá em supermercados.
} 


\section{DESENVOLVIMENTO: COLETA DE DADOS}

Para cada livro que havia nos estandes, foram recolhidos os seguintes dados: Título, autor, editora, gênero literário - informado pela editora, gênero literário - informado pela livraria, projeto gráfico circunscrito à ilustração (capa e miolo).

Como ilustração, para a realização deste trabalho, entende-se a imagem que acompanha um texto alfabético, seja sua técnica desenho, pintura, fotografia, etc. "A noção de ilustração afasta-se da ideia de técnica, de estilo e de enfeite e aproxima-se da noção de uma prática que comunica visualmente um conteúdo que a acompanha, seja ela de forma complementar ou suplementar" (CAVALCANTE, 2010). Portanto, não foram consideradas como ilustradas as capas que apresentam composições exclusivamente tipográficas e padronagens com intensões não figurativas (como listras, retângulos ou manchas de tinta), assim como também não foram considerados como sendo ilustrados livros que apresentam em seu miolo simples repetições de elementos gráficos da capa (seja para formar padronagens ou para vinhetas), enfeites de cabeçalho e rodapé ou aqueles que apresentam somente gráficos matemáticos.

Para identificar possíveis tendências, dividiram-se as ilustrações em três categorias: imagens fotográficas, cuja técnica é a fotografia e a fotomontagem, sejam elas analógicas ou digitais; Imagens sintéticas ${ }^{3}$, cuja técnica pode variar entre desenho e pintura, sejam eles elaborados por meios tradicionais ou digitais; e imagens de conteúdo misto, que são aquelas que misturam as categorias anteriores.

Houve certa dificuldade no estabelecimento dos gêneros aos quais os livros pertenciam, principalmente os de ficção. Procurou-se ver em cada ficha catalográfica as palavras-chaves, que normalmente incluem o gênero literário ao qual o livro em questão pertence. No entanto, muitas vezes a informação que constava nas fichas se apresentava diferente dos padrões formais de caracterização de gênero literário. Quando esse caso se apresentava, recorreu-se ao site da editora do livro para procurar referências ao gênero no catálogo, em press releases e afins. Infelizmente, por vezes, nem assim foi possível ${ }^{4}$. Em decorrência deste fato, há definições de gênero segundo a editora não-padronizadas, como "Jesus Cristo - Ficção", ou genéricas como "Ficção norteamericana", ou ainda definidas em função do público alvo como em "infantil" ou "infanto-juvenil", como se um livro dirigido para crianças não pudesse ser de terror, fantasia etc.

Baseada nesta experiência, constatou-se então que há uma diferença entre a categorização de gêneros vigente no discurso acadêmico e aquela proposta pelo mercado editorial. Enquanto o discurso acadêmico apresenta categorias tradicionais, como romance, terror, epopeia etc. $O$ mercado oscila entre a manutenção do discurso acadêmico e a criação de um discurso mais próximo da objetividade do varejo, com a promoção dos assuntos abordados, como se pode perceber em exemplos como "televisão programa" ou com uma definição genérica, como em "ficção brasileira".

\footnotetext{
${ }^{3}$ Esta categoria foi baseada nos estudos do texto El siglo de la imagen analógica, de Pierre Sorlin. O autor apresenta a expressão imagem sintética para tratar especialmente de pinturas e desenhos que, de acordo com ele, embora não tenham a pretensão de serem totalmente realistas (totalmente fidedignas aos modelo e acontecimentos na ordem cronológica, por exemplo) são fieis a ideia do autor e que pressupõem uma aprendizagem prévia do leitor de um léxico dos elementos representados.

${ }^{4}$ Posteriormente, procurou-se as informações no catálogo do site da Fundação Biblioteca Nacional, mas muitas vezes esta informação era ausente ou tão vaga quanto às apresentadas nas fichas catalográficas dos livros.
} 
Devido a esta dificuldade, para facilitar a compreensão e simplificar as análises, num primeiro momento, dividiu-se os livros em duas grandes categorias: os gêneros formalmente considerados como não-ficção (tais como biografia, auto-biografia, livros técnicos, história, guia turístico, culinária, moda etc.) e os considerados livros de ficção (romance, comédia, terror, fantasia, mistério, ficção-científica etc.).

\subsection{Análise geral}

Ao total, foram analisados 233 livros, conforme os seguintes gráficos:

\section{Análise geral: Toda a amostra - llustrações de capa}

घem ilustração - 28 mimg. fotográfica - 121 img. sintética - 80 misto - 4

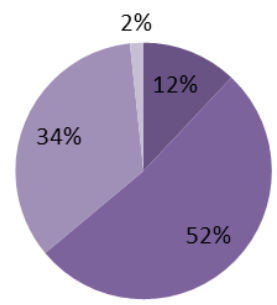

\section{Análise geral: Fiç̧ão - Ilustrações de capa}

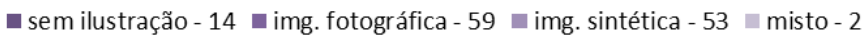

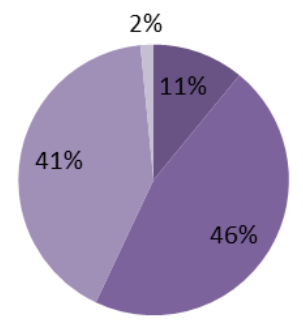

\section{Análise geral: Não-ficção - Ilustrações de miolo}

— sem ilustração - 37 mimg fotográfica - 40 img sintética - 11 misto - 17

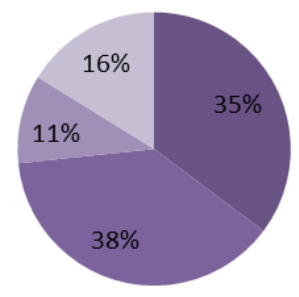

\section{Análise geral: Não-ficção - Ilustrações de capa}

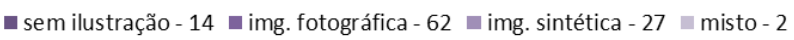

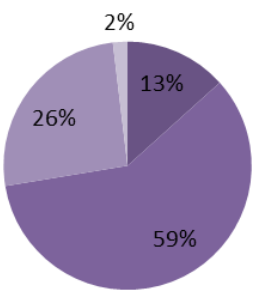

\section{Análise geral: Toda a amostra - llustrações de miolo}

घ sem ilustração - 148 घimg fotográfica - 41 img sintética - 25 misto - 19

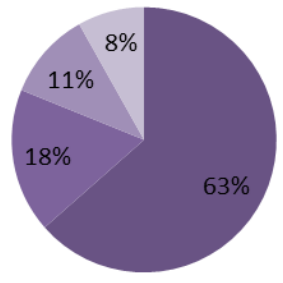

\section{Análise geral: Ficção - Ilustrações de miolo}

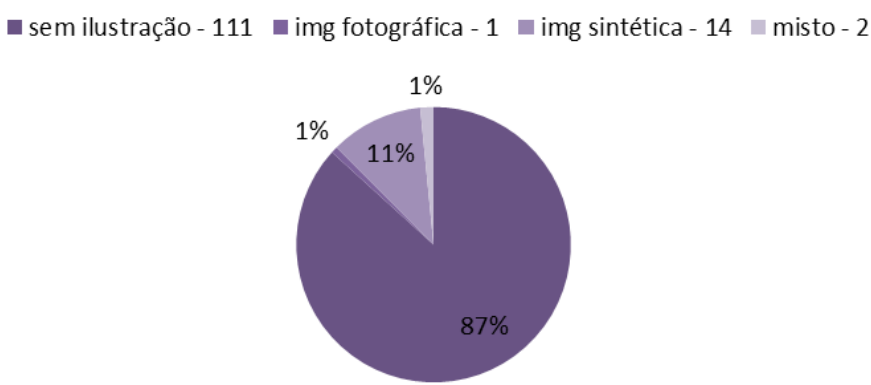

Figura 1 - Gráficos relativos à totalidade dos livros pesquisados Fonte: Elaborado pela autora, com base na pesquisa realizada.

Entre as análises que podem ser atingidas utilizando as informações gerais, uma é a de que a maioria dos livros de ambos os estandes (205, ou 66\%) possui algum tipo de imagem na 
sua capa, mesmo aqueles que não têm ilustrações em seu miolo. Na totalidade da amostra analisada as imagens utilizadas nas capas, em sua maioria (121, ou 52\%), são fotográficas ${ }^{5}$.

A presença de ilustrações no miolo é significativamente maior nos livros de não-ficção (68, ou $62 \%)$ do que naqueles considerados livros de fiç̧ão (17, ou $23 \%)$. No entanto, enquanto o primeiro grupo apresenta maioria de ilustrações fotográficas (40, ou 35\%), o segundo tem como predomínio imagens sintéticas (14, ou 11\%).

Nos chamados livros de não-ficção, as fotos, desenhos e pinturas são utilizados para comunicar ao leitor informações próprias da linguagem das imagens como passo-a-passo ilustrado em livros de culinária e documentações visuais que "atestam", funcionando como um "lastro" de veracidade, que determinado fato, coisa ou pessoa existiu. Predominam nelas um caráter didático que as características específicas da linguagem imagética podem favorecer.

Nos livros de ficção, há uma grande maioria de livros sem imagens no miolo (111, ou 87\%). Essa situação só muda drasticamente nos livros categorizados pela própria editora como infantis (4), cuja a presença de ilustração na capa e no miolo é $100 \%$; e nos infantojuvenis (11), dos quais 27,3\% tem seu miolo ilustrado. Quando a classificação da editora muda para juvenil (3), já não há nenhum exemplar com o miolo ilustrado. Nos livros que não são declarados pelas editoras como específicos para o público "não-adulto", destacam-se os livros de poesia (3), dos quais $66,7 \%$ tem o miolo ilustrado. Se descontarmos os infantis, os infantojuvenis, os juvenis e os de poesia (seguindo a classificação da editora), os livros de literatura de ficção com ilustração no miolo são apenas 9. São eles: Onde a lua não está, Eu me chamo Antônio (que é caracterizado pela Livraria Cultura como poesia), A menina que roubava livros, $O$ códex dos caçadores das sombras (que é caracterizado pela Livraria Cultura como juvenil), Reinações de Narizinho (caracterizado pela Livraria Cultura como infantil), A bela história do Pequeno Príncipe (que é caracterizado pela Livraria Cultura como infanto-juvenil), Game of Thrones: A pop-up guide to Westeros (cuja classificação de gênero por parte da editora não foi encontrada), Decameron e $O$ Livro das Princesas (que é caracterizado pela Livraria Cultura como juvenil).

É interessante notar que é preciso definir, como sendo dirigidos ao público adulto, os livros não categorizados como sendo do gênero infantil, infanto-juvenil e juvenil. É como se houvesse uma "adulto-normatividade" e somente os livros não dirigidos aos adultos necessitassem de uma categorização em função de público. Isso levanta o questionamento de uma possível super segmentarização do mercado em geral e que se reflete no mercado editorial. Tem-se as noções de adolescência, pré-adolescência, tween, jovens, jovens adultos, adultos, entre outras, cada uma com seus produtos de consumo próprios que devem demarcar claramente a distinção entre seus consumidores. Tem-se livros para crianças (infantis e infanto-juvenis), adolescentes (juvenis e infanto-juvenis novamente) e jovens

\footnotetext{
${ }^{5}$ A autora propõe a hipótese de que nas capas a predominância de imagens fotográficas sobre desenhos e pinturas se deva, pelo menos em parte, ao grande uso de bancos de imagem (também conhecidos como banco de fotografias, que embora também vendam e licenciem desenhos e pinturas, têm a maior parte de seu acervo formado por fotos) que são mais baratos e rápidos do que contratar um ilustrador ou um capista que ilustre. Este recurso é largamente utilizado por diversas mídias, como se pode ver neste trecho informativo de um famoso banco de imagens, o iStock: "Todos os dias você vê milhares de imagens em revistas, embalagens, cartazes, online e na TV. Mas muito poucas destas imagens foram criadas especificamente para aquele produto, promoção ou conceito - o que você está vendo é material de bancos de fotografias. Essas fotografias (chamadas de stock) são imagens já prontas que são licenciadas para uso em seus materiais de propaganda ou promoção para ilustrar objetos, conceitos ou ideias específicos." (fonte: http://portuguesbrasileiro.istockphoto.com/help/about-us Acesso em 13 de maio de 2014)
} 
adultos (como é o caso declarado, por exemplo, da Galera, selo da Record). Segundo CORSO, 2006:

A partir da modernidade, começou a haver uma distinção entre produtos culturais para adultos e produtos culturais para crianças, nosso tempo levou isso ao extremo, e cada idade passou a ter seus produtos bem delimitados. A cultura assimilou as leis do mercado, incorporando suas prerrogativas de consumo e publicidade.

É como se no livro de literatura dirigido ao público adulto, a imagem só fosse "permitida" para vender (na capa), enquanto o livro de não-fiç̧ão usa com frequência as possibilidades e facilidades da imagem para comunicar diversas informações. Se considerarmos também outros veículos de informação que comumente veiculam a palavra escrita, como jornais e revistas, é possível ver que a ilustração (tanto a imagem fotográfica quanto a imagem sintética) é massivamente presente. $O$ livro de literatura dirigido ao público adulto é quase um "bastião de resistência" à imagem.

Outro ponto que é interessante observar é a diminuição da proporção de ilustração no miolo dos livros de literatura em função da idade do público (mais uma vez, segundo a editora): $100 \%$ nos infantis, $27,3 \%$ nos infanto-juvenis e $7,5 \%$ nos adultos (o que equivale a 6,3\% da amostragem total). Isso levanta a questão de uma possível "desalfabetização" de imagens simultânea à alfabetização das palavras alfabéticas, nas palavras de Marilda Castanha, na obra $O$ que é qualidade em ilustração no livro infantil e juvenil - Com a palavra o ilustrador:

A partir do momento em que se é alfabetizado, que se aprende a decodificar os caracteres dos textos, gradativamente os detalhes como a expressão das personagens, elementos do cenário, percepção de formas e cores, que antes eram determinantes para a compreensão da história, passam a ficar em segundo (ou último) plano. É como se, aos poucos, durante a trajetória de uma pessoa na vida escolar, ela se "desalfabetizasse" das imagens. Não é por acaso que muitos adultos não se sentem estimulados a visitar museus, galerias de arte ou bienais. O que se faz ao ler um livro de imagens - observar, deduzir, inferir - é o mesmo diante de uma obra de arte. $O$ receio de não entender e, principalmente, opinar sobre o que vê, desencoraja muito o adulto a ver obras de arte.

Uma vez que havia mais de 34 gêneros literários diferentes, segundo a classificação das editoras, foi preciso recolher também as informações dadas pelas livraria, que classifica os livros de uma maneira única e sistemática, mais de acordo com o discurso acadêmico. Muitas vezes para fins de simplificação das informações, foi preciso juntar dois ou mais gêneros dados pelas editoras, como por exemplo "Jesus Cristo - Ficção" e "Ficção americana" foram colocados na categoria "Ficção" e "História geral" e "História brasileira" foram colocados juntos na categoria "História".

Os gêneros que, ao total, mais se utilizam de imagem no miolo são: História (20), biografia (7), infantil, culinária, ficção e não-ficção (cada um com 4), de acordo com as editoras, e história (22), biografia (13) e infantil (6) de acordo com as livrarias.

\subsection{Comparação entre as amostras}


Lançamentos: Toda a amostragem - Ilustração de capa

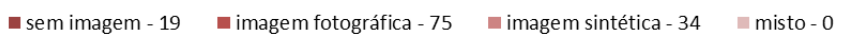

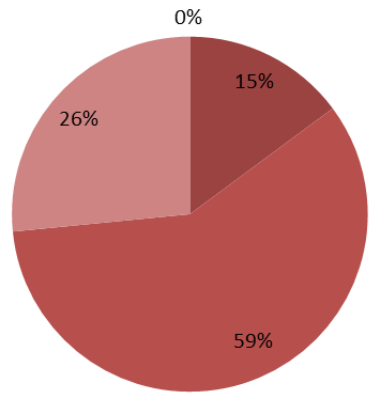

Lançamentos: Não-ficção - Ilustração de capa

n sem ilustração - 9

n imagem fotográfica - 36

nimagem sintética - 7

misto - 0

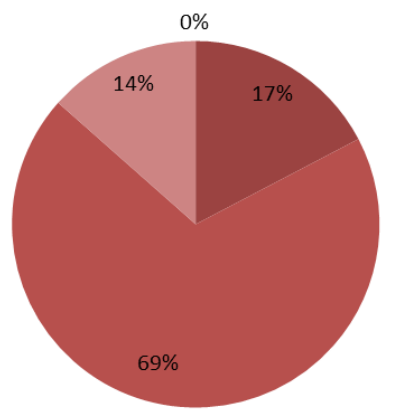

Lançamentos: Toda a amostragem - llustração de miolo

- sem ilustração - 93

- imagem fotográfica - 23

imagem sintética - 6

misto- 6

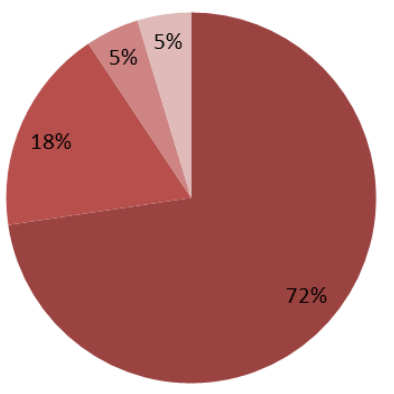

Lançamentos: Não-ficção - llustração de miolo

n sem ilustração - 23

- imagem fotográfica - 22

n imagem sintética - 2

misto - 5

" sem ilustação - 70

Lançamentos: Ficção - Ilustração de miolo
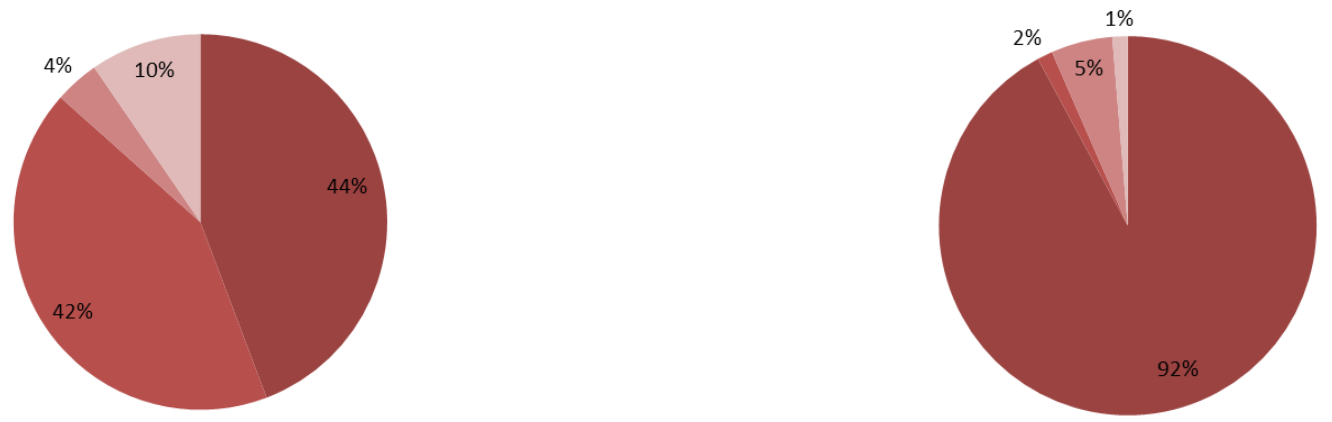

Figura 2 - Gráficos relativos aos livros encontrados no estande de lançamentos Fonte: Elaborado pelo autor, com base na pesquisa realizada. 


\section{Mais vendidos: Toda a amostragem - llustração de capa}

घem ilustração - 9 img fotográfica - 46 img sintética - 46 misto - 4

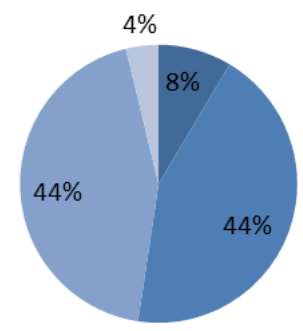

Mais vendidos: Não-ficção -

Mais vendidos: Ficção llustração de capa llustração de capa

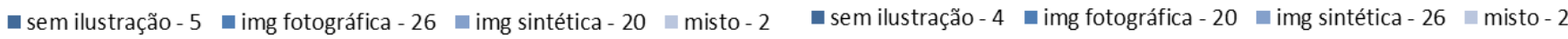

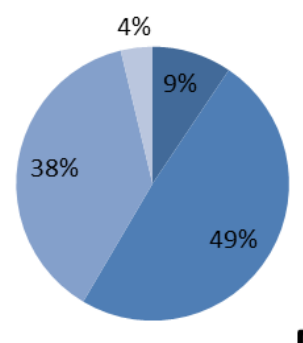

\section{Mais vendidos: Toda a amostragem - llustração de miolo}

घem ilustração - 55 img fotográfica - 18 img sintética - 19 misto - 13

\section{Mais vendidos: Não-ficção - Ilustrações de miolo}

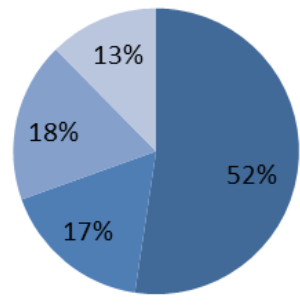

घem ilustração - 14 img fotográfica - 18 img sintética - 9 misto - 12

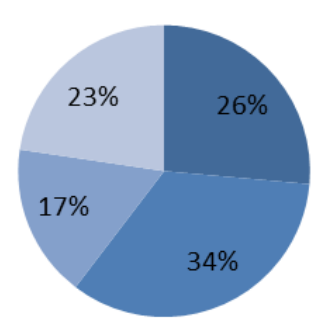

Mais vendidos: Ficção Ilustração de miolo

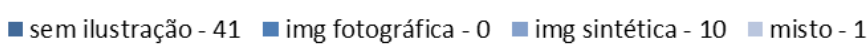

Figura 3 - Gráficos relativos aos livros encontrados no estande de mais vendidos Fonte: Elaborado pelo autor, com base na pesquisa realizada.

Comparando os diferentes estandes, também é possível chegar a algumas informações relevantes. No estande de lançamentos temos um total de 128 livros, no de mais vendidos, 
105 livros. Enquanto no estande de lançamentos, há uma predominância de livros de ficção (76, ou $59 \%$ ), no estande de mais vendidos há um equilíbrio entre ficção e não ficção (52\% e $53 \%$, respectivamente).

No estande de lançamentos 43 dos livros de não-ficção (83\%) e 66 dos de ficção (87\%) tem sua capa ilustrada. Já no estande de mais vendidos esse percentual aumenta com 48 livros de não-ficção (91\%) e 48 de ficção (92\%) com a capa ilustrada. Uma possível conclusão é que a presença de ilustrações nas capas dos livros pode influenciar a compra.

As ilustrações mais presentes nas capas de livros de não-ficção são imagens fotográficas, no estande de lançamentos (36, ou 69\%) e no de mais vendidos (26, ou $49 \%$ ). Nos livros de ficção isso varia: temos uma maioria de imagens fotográficas no estande de lançamentos (39, ou 51\%) e uma predominância de capas com imagens sintéticas no de mais vendidos (26, ou $50 \%)$.

No primeiro estande, dos 76 livros de ficção analisados, somente quatro que não eram considerados pela própria editora como pertencentes aos gêneros infantil, juvenil, infantojuvenil ou poesia, e continham ilustrações no miolo (5,3\%). No estande de mais vendidos, há um aumento sutil: foram analisados 52 livros de ficção e destes 5, nas mesmas considerações, continham ilustrações em seus miolos (9,6\%).

As ilustrações mais presentes nos miolos de livros de não-ficção permanecem sendo fotográficas (22, ou $42 \%)$, no estande de lançamentos e no de mais vendidos (18, ou $34 \%$ ) e as dos livros de ficção também permanecem sendo as imagens sintéticas no estande de lançamentos (4, ou $5 \%$ ) e no de mais vendidos (10, ou $19 \%)$.

No estande de lançamentos, os gêneros que mais continham ilustrações, segundo a editora, são história (9), biografia (5) e não-ficção (3). E história (12), biografia (8) e poesia (3), segundo a livraria. Já no estande de mais vendidos, os gêneros que mais continham ilustrações, segundo a editora, são história (11), infantil (4) e infanto-juvenil e culinária (com 3 cada). E história (11), infantil (6) e biografia (5), segundo a livraria.

\section{CONCLUSÃO}

Das relações e conclusões que podem ser tiradas dos dados apresentados, a mais relevante para este estudo é a constatação da baixa oferta de títulos de literatura ilustrados dirigidos para o público adulto. A grande maioria dos miolos de livros de ficção não é ilustrada, fato que não ocorre nos livros de não-ficção. Há um aumento na ocorrência de ilustrações nos miolos de tanto de livros de ficção quanto de não-ficção comparando o estante de lançamentos (expectativa de venda por parte das editoras e livreiros) com o estande de mais vendidos (compra efetiva por parte do consumidor), o que pode sinalizar que a presença de imagens no corpo do livro seja um fator que impulsione a compra.

No entanto, vê-se que a presença de ilustração na capa se mostra largamente utilizada e, pela relação de aumento de ocorrência em comparação do estande de lançamentos e com o estande de mais vendidos, pode-se concluir que ela cumpre seu papel de atração do leitor. A fotografia mostrou-se uma forte tendência em capas.

É possível observar uma cacofonia em relação ao gêneros dos livros. A academia tem uma definição formal engessada pela tradição que parece estar longe da realidade do mercado, as editoras não fazem questão de apresentar o gênero do seu livro para o leitor ou o apresentam de formas não-padronizadas, genéricas ou ainda definidas em função do público alvo e, finalmente, as livrarias, por terem seções pré-determinadas, parecem tentar fazer uma ponte entre as definições formais e as utilizadas pelas editoras. Muitas vezes um mesmo livro é categorizado de maneira diferente pela editora e pela livraria. 
Apesar de ser uma amostragem limitada, podemos inferir que um dos desafios do Design está centrado em ter reconhecido não apenas o seu lugar como participante de todo o processo editorial, mas, em especial, no âmbito da temática do presente artigo, ter a imagem reconhecida como participante da formação dos indivíduos, com potência para sua ressignificação. Em suma, foi possível observar que enquanto o conteúdo verbal ficcional participa da reconstrução dos sujeitos, a imagem, quando não ignorada, se mantém em posição prioritariamente subalterna. 


\section{REFERÊNCIAS}

CAVALCANTE, Nathalia Chehab de Sá. Ilustração: Uma prática passível de teorização. 2010. 285 f. Dissertação (mestrado) - Pontifícia Universidade Católica do Rio de Janeiro, Curso de Pós-Graduação em Design.

CORSO, Diana Lichtenstein; CORSO, Mário. Fadas no divã: psicanálise nas histórias infantis. 1a ed. Rio Grande do Sul: Artmed Editora, 2006.

ISTOCK. Sobre nós. Disponível na internet pop:

http://portuguesbrasileiro.istockphoto.com/help/about-us Acesso em 13 de maio de 2014.

OLIVEIRA, leda de. $\mathbf{O}$ que é qualidade em ilustração no livro infantil e juvenil: com a palavra o ilustrador. 1a ed. São Paulo: DCL, 2008.

SORLIN, Pierre de. El siglo de la imagen analógica. Buenos Aires: La Marca Editora, 2003. 